\title{
Erratum to: Atraumatic splenic rupture, an underrated cause of acute abdomen
}

\author{
Massimo Tonolini ${ }^{1}$ • Anna Maria Ierardi ${ }^{2}$ - Gianpaolo Carrafiello ${ }^{2}$
}

Published online: 29 June 2016

(C) The Author(s) 2016

\section{Erratum to: Insights Imaging}

DOI 10.1007/s13244-016-0500-y

The name of the author Anna Maria Ierardi was rendered wrongly in the original publication but has since been corrected. The publisher apologises for this error and the inconvenience caused.

The online version of the original article can be found at doi:10.1007 /s13244-016-0500-y.

$\triangle$ Massimo Tonolini mtonolini@sirm.org

1 Department of Radiology, "Luigi Sacco" University Hospital, Via G.B. Grassi 74, 20157 Milan, Italy

2 Interventional Radiology - Department of Radiology, University of Insubria, Viale Borri 57, 21100 Varese, Italy 